\title{
Drugs in sport - testing results from the South African Laboratory 1995 - 2002
}

\section{P J van der Merwe (PhD)}

South African Doping Control Laboratory, Department of Pharmacology, University of the Free State, Bloemfontein

\begin{abstract}
Objective. To summarise the results of the past 8 years obtained at the South African Doping Control Laboratory and to compare the results with international statistics.

Method. Screening procedures were performed on 14017 urine samples collected from competitors in 54 different sporting codes during the period 1995 - 2002. Samples were analysed using gas chromatography and gas chromatography/mass spectrometry for the presence of prohibited substances, which are listed by the International Olympic Committee (IOC).

Results. The results obtained were compared with those of the IOC-accredited laboratories. Prohibited substances were detected in 300 samples (2.14\%), of which $45.6 \%$ contained anabolic agents and $34.6 \%$ stimulants. The positive samples from the IOC laboratories contained $58.7 \%$ anabolic agents and $20.8 \%$ stimulants. Testosterone and nandrolone were the anabolic agents most frequently detected in positive samples, both in South Africa and internationally. The ephedrines as a group accounted for most stimulants detected in positive samples.

Conclusion. It is of concern that the percentage of positive samples $(2.14 \%)$ obtained in our laboratory is higher than the $1.70 \%$ in IOC laboratories. It is therefore necessary that doping control to curb the use of prohibited substances should continue and expand.
\end{abstract}

\section{CORRESPONDENCE}

\section{P J van der Merwe}

Department of Pharmacology

University of the Free State

PO Box 339

Bloemfontein

9300

Tel: 051-4013182

Fax: 051-444 1523

E-mail: gnfmpvdm.md@mail.uovs.ac.za

\section{Introduction}

In 1982 the Department of Pharmacology at the University of the Free State was approached by several sports administrators to analyse urine samples from competitors for the presence of prohibited substances. An increasing number of competitors had seemingly turned to the use of drugs in an effort to enhance performance. Analytical procedures were set up for the detection of all chemical substances banned in sport according to the official list of the International Olympic Committee (IOC), ${ }^{2}$ which is revised and published annually.

In 1983 urine samples collected at 3 different sporting events were tested for a few stimulants. ${ }^{1}$ Since 1984 , screening for all banned stimulants and narcotics was performed on all urine specimens collected at sporting events, and from 1986 this included screening for anabolic steroids. ${ }^{3-5}$ Soon thereafter diuretics and $\beta$-Blockers were added to the array of testing procedures.

After thorough testing and inspection by the IOC (SubCommission Doping and Biochemistry in Sport), accreditation was granted to the South African Doping Control Laboratory (Department of Pharmacology, University of the Free State) in 1995. The laboratory is therefore authorised to analyse urine samples from international competitors and athletes. Annually each IOC-accredited laboratory must supply the IOC with statistics of the samples they have analysed in order to allow the IOC to construct a global picture concerning doping in sport.

The aim of this study was to summarise the results of the past 8 years of dope testing at the South African Laboratory (from the time IOC accreditation was awarded), and to compare these results with a summary of statistics from the IOCaccredited laboratories.

\section{Method}

All urine samples received in the laboratory were screened for all the groups of substances on the IOC list. Each group has its own unique method of analysis as described below:

- Stimulants - alkaline extraction of urine with ether and injection of the extract onto a gas chromatograph equipped with a nitrogen-specific detector.

- Narcotic analgesics - hydrolysis of urine followed by alkaline extraction, derivatisation and gas chromatography with a mass selective detector (GC/MSD).

- Anabolic agents - GC/MSD after deconjugation and derivatisation of the urine extracts.

- Diuretics - methylation of the urine extract followed by GC/MSD 
- $\beta$-blockers - after hydrolysis and derivatisation the urine extract is injected onto a GS/MSD (screening for $\beta$-blockers is not performed routinely but only for certain events).

The screening procedure results are compared with reference standards and the possible presence of a doping agent and/or metabolite is indicated. Confirmatory analysis must be performed on positive results to provide unequivocal identification of the drug and/or metabolite. ${ }^{5}$

During 1995 - 1997 the decision whether to test athletes within their code rested with the individual sport federations. The latter were responsible for collecting and dispatching samples to the laboratory, and received the results directly. In 1997 the South African Institute for Drug Free Sport (SAIDS) was appointed and empowered in terms of Act No. 14 of 1997 to be the only body authorised to govern dope testing in South Africa. Subsequently, SAIDS was responsible for all urine collection and result management, thus divesting the individual Sports Federations from any responsibility. From 1998 - 2002 all samples were received from SAIDS.

Urine samples were collected from provincial, national and international competitors, including competitors from aboard competing in South Africa. The identity of the competitors was unknown to the laboratory and it was therefore not possible to distinguish between local and foreign competitors. A few samples were received from Namibia, Kenya, Mauritius and Nigeria.

\section{Results and discussion}

Approximately 1500 samples were analysed annually except for the years 1999, 2001 and 2002 (Table I). In 1999 with the All Africa Games held in Johannesburg, more than 400 samples were analysed over a period of 10 days ${ }^{6}$ and this accounted for the increase in the number of samples for that year. The SAIDS expanded their testing programme in 2001 and this accounted for the increase in the number of samples for 2001 and 2002. A total of 14017 samples were analysed over the 8 years.

The percentage of positive doping cases each year is also given in Table I, fluctuating between $1.49 \%$ in 1998 and $3.02 \%$ in 1999 , with an average of $2.14 \%$. This is higher than the IOC laboratories' average of $1.70 \%$ (range $1.61-1.90 \%$ ).

Table II gives the number of different sports in which competitors were tested. The SAIDS systematically increased the number of sports where testing was conducted, totalling 54 altogether. Table II also indicates that in many sports no

$\begin{aligned} & \text { TABLE I. Number of samples analysed each year and } \\
& \text { percentage of positive samples }\end{aligned}$
\begin{tabular}{lcc}
\hline Year & Number of samples & $\%$ Positive \\
\hline 1995 & 1384 & 2.82 \\
1996 & 1549 & 1.94 \\
1997 & 1324 & 2.27 \\
1998 & 1478 & 1.49 \\
1999 & 2119 & 3.02 \\
2000 & 1451 & 1.72 \\
2001 & 2321 & 1.68 \\
2002 & 2391 & 2.20
\end{tabular}

competitors tested positive for the use of banned substances.

Urine samples for doping control can be collected from competitors in-competition (immediately before, during or immediately after an event) or out-of-competition (during the training period both during and out of the competitive season). Anabolic agents are considered to be training drugs, that is, drugs taken during the off-season training period so that they will not be present in the body during competition. Out-of-competition testing, where the sampling officer collects competitors' urine samples at home or at the training place, was instituted to curb the use of anabolic agents.

The percentage of samples received from out-of-competition testing locally as well as internationally is given in Fig. 1. More than $40 \%$ of the total number of samples analysed internationally each year were from out-of-competition testing, while this figure is far lower in South Africa. However, there was a large increase in 2002, which is almost equal to the international figure. The percentage of positive samples from local out-of-competition testing is given in Table II.

The different groups of substances found in positive samples are given in Fig. 2. Of the 300 positive samples, almost half $(45.4 \%)$ contained anabolic agents, while $34.6 \%$ contained stimulants and $15 \%$ diuretics. Narcotics (1.9\%),

\begin{tabular}{|c|c|c|c|c|}
\hline \multirow[b]{2}{*}{ Year } & \multicolumn{2}{|c|}{$\begin{array}{l}\text { Number of different sports } \\
\text { involved and percentage of } \\
\text { sports with positive doping } \\
\text { cases }\end{array}$} & \multicolumn{2}{|c|}{$\begin{array}{l}\text { Number of samples } \\
\text { from out-of-competition } \\
\text { testing and percentage } \\
\text { samples containing banned } \\
\text { substances }\end{array}$} \\
\hline & Number of sports & $\%$ Positives & Number of samples & $\%$ Positives \\
\hline 1995 & 24 & 37.5 & 104 & 1.9 \\
\hline 1996 & 16 & 62.5 & 280 & 0 \\
\hline 1997 & 22 & 54.5 & 93 & 3.2 \\
\hline 1998 & 23 & 52.2 & 292 & 0.7 \\
\hline 1999 & 33 & 60.2 & 204 & 3.9 \\
\hline 2000 & 36 & 27.2 & 307 & 0.3 \\
\hline 2001 & 44 & 36.4 & 585 & 1.5 \\
\hline 2002 & 45 & 42.2 & 959 & 0.7 \\
\hline
\end{tabular}

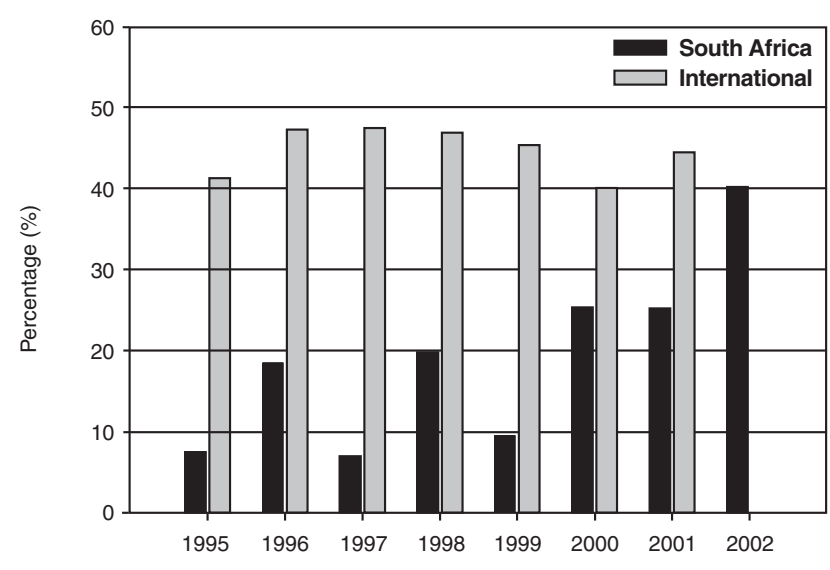

Fig.1. Percentage of samples from out-of-competition testing. 
$\beta$-Blockers (1.5\%) and 'others' (1.6\% - cannabis and masking agents) were found in only a few samples. The IOC laboratories' statistics differ in that more positive samples contained anabolic agents (58.2\%), with less stimulants $(20.8 \%)$ and diuretics (3.8\%). The group 'others' positive samples $(15 \%)$ included mainly cannabis, of which there is a high incidence of use internationally. Cannabis use seems to be not such a big problem in South African sport although it is possible that the sports where such abuse may be widespread were not adequately targeted.
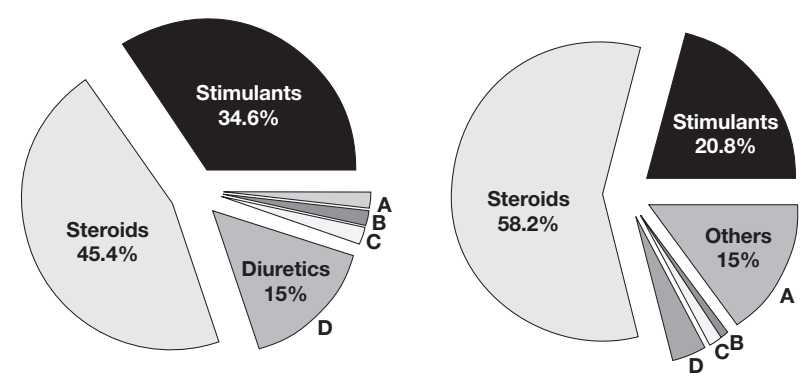

Fig. 2. Spread of positive samples among the different groups of substances ( $A=$ cannabis and masking agents (RSA 1.6\%, IOC 15\%); B = $\beta$-blockers (RSA 1.5\%, IOC 0.7\%); $C=$ narcotics (RSA 1.9\%, IOC 1.5\%); $D=$ diuretics (RSA $15 \%$, IOC $3.8 \%$ ).

The main stimulants and anabolic agents identified in positive samples are given in Figs 3 and 4, where they are expressed as a percentage of the number of positive samples containing stimulants and anabolic agents, respectively. In South Africa as well as internationally the ephedrines (ephedrine, norpseudoephedrine, pseudoephedrine, norephedrine and methylephedrine), which are active ingredients in many medications for flu and coughs and can be bought at pharmacies without a prescription, accounted by far for most of the positive samples containing stimulants. Fencamfamine (Reactivan) was more frequently detected in South Africa than in other countries, while amphetamine, cocaine and caffeine showed up more frequently in other countries. Testosterone and nandrolone accounted for the most positive samples containing anabolic agents, both in South Africa and internationally. In South Africa there is an increasing use of stanozolol. This anabolic agent and

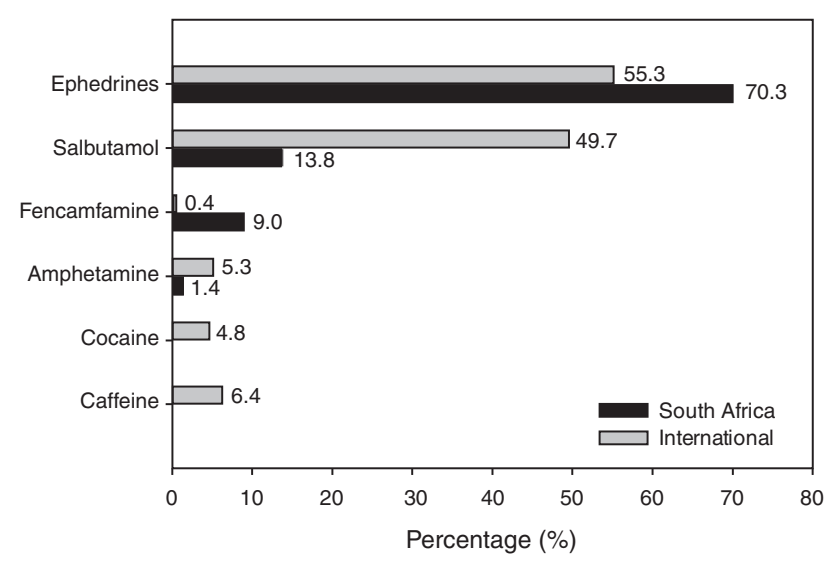

Fig. 3. Main stimulants identified in positive samples.

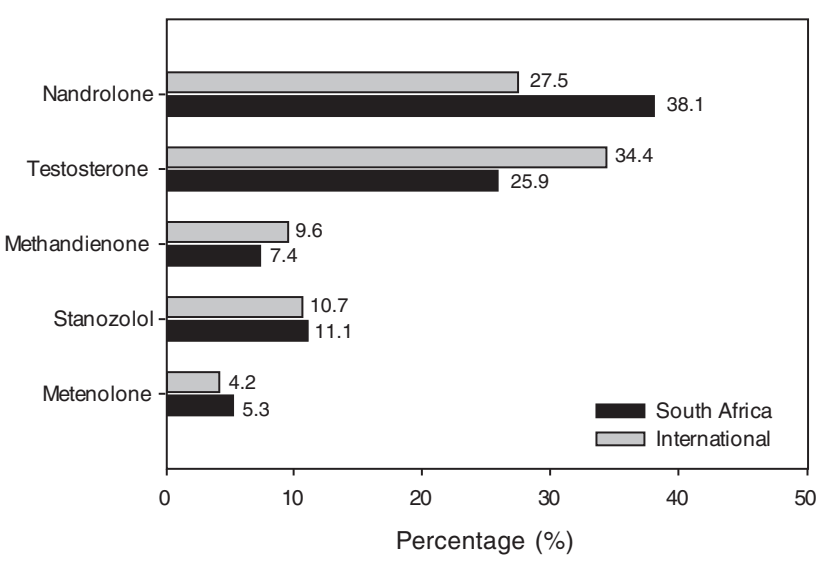

Fig. 4. Main anabolic agents identified in positive samples.

methandienone, are not registered products in South Africa and can only be obtained on the 'black market'. In some urine samples 3 or 4 different anabolic agents were identified in the same sample, which shows the extreme to which athletes are prepared to go in an effort to gain advantage from the use of these agents. Although there is severe punishment for competitors who violate the rules (up to 2 years ban from any competition for the use of anabolic agents) they are still prepared to take chances and use banned substances in the hope that they will not be caught.

There is a similarity in the pattern of stimulants and anabolic agents identified in positive doping cases between South Africa and the IOC-accredited laboratories.

The results of this study show that there was a decline in the percentage of positive samples since 1990 - 1991 when more than $5 \%$ of the samples tested positive. ${ }^{3}$ However, the average percentage of positive samples $(2.14 \%)$ is still higher than the international average of $1.7 \%$. It is still a concern that some of South Africa's top competitors are unaware that medication could contain banned substances, as illustrated by the many samples that tested positive for the ephedrines.

The question may be asked whether the dope testing programme has the desired effect. By way of illustration, the percentage of positive samples obtained each year for 4 different sports is given in Table III. For sports A, B and C positive samples were recorded each year with no decline. For sport $D$ a high percentage of positive samples was recorded in 1995. No testing was done in the following 3 years, mainly because the Federation involved did not do any testing. When testing was resumed by SAIDS in 1999, a high number of positive samples were again obtained. During 2000 2002, more extensive testing was done on the competitors of that sport but no positive samples were identified. This indicates that the institution of regular testing had the desired effect.

\section{Conclusion}

It is of concern that there has been no decline in the number of positive samples during the past 8 years. It is therefore necessary to continue to monitor the use of prohibited substances in sport. 
TABLE III. Percentage of positive samples in certain sports

\begin{tabular}{lcccc}
\hline Year & Sport A & Sport B & Sport C & Sport D \\
\hline 1995 & 1.6 & 1.4 & 1.1 & 16.7 \\
1996 & 0.4 & 3.2 & 0.5 & NT \\
1997 & 1.1 & 1.0 & 2.2 & NT \\
1998 & 1.1 & 1.5 & 0.7 & NT \\
1999 & 2.0 & 3.1 & 0.4 & 9.9 \\
2000 & 1.0 & 1.9 & 1.5 & 0.0 \\
2001 & 1.5 & 3.1 & 0.3 & 0.0 \\
2002 & 3.4 & 2.3 & 0.8 & 0.0 \\
NT $=$ not tested. & & & &
\end{tabular}

Competitors should realise that there are no short cuts to success. Success can only be earned by disciplined hard work and commitment.

All credit should be given to SAIDS for their expanded programme of testing in South Africa and they need to be fully supported by the South African sporting community.

\section{Acknowledgement}

We wish to thank SAIDS for providing finances for the analysis.

\section{REFERENCES}

1. Hundt HKL, van der Merwe PJ, van Velden DJ. Drugs in sport: a report of laboratory investigations into the prevalence of their use in South Africa. S Afr Med J 1984; 66: 878-81.

2. International Olympic Committee. List of Prohibited Classes of Substances and Prohibited Methods. Lausanne: International Olympic Committee, Medical Commission, 2001.

3. van der Merwe PJ. Verbode middels in sport: Resultate van toetsing vir die tydperk 1986 - 1994. South African Journal Sports Medicine 1995; 2 (2) 15-18.

4. van der Merwe PJ, Hundt HKL, Müller FO, van Velden DP. Drugs in sport - the first 5 years of testing in South Africa. S Afr Med J 1988; 74: 161-2.

5. van der Merwe PJ, Kruger HSL. Drugs in sport - the results of the past 6 years of dope testing in South Africa. S Afr Med J 1992; 82: 151-3.

6. van der Merwe PJ, Kruger HSL, Pieterse JW, Pretorius MJ, de Kock NJ Report on the doping control during the 7th All Africa Games in South Africa. South African Journal Sports Medicine 2000; 7(3): 14-16. 